\title{
dspace.vutbr.cz
}

\section{Model-based Electronic Expansion Valve Feed- forward Control for Electrified Automotive Vapor Compression Refrigeration System}

\author{
GLOS, J.; ŠOLC, F.; VÁCLAVEK, P.
}

Proceedings of the IECON 2020 - The 46th Annual Conference of the IEEE Industrial Electronics Society, pp. 2059-2056

elSBN: 978-1-7281-5413-8

ISSN: 2577-1647

DOI: https://doi.org/10.1109/IECON43393.2020.9255028

Accepted manuscript

(C2020 IEEE. Personal use of this material is permitted. Permission from IEEE must be obtained for all other uses, in any current or future media, including reprinting/republishing this material for advertising or promotional purposes, creating new collective works, for resale or redistribution to servers or lists, or reuse of any copyrighted component of this work in other works. GLOS, J.; ŠOLC, F.; VÁCLAVEK, P. "Model-based Electronic Expansion Valve Feed-forward Control for Electrified Automotive Vapor Compression Refrigeration System", IECON 2020 - The 46th Annual Conference of the IEEE Industrial Electronics Society. DOI:

10.1109/IECON43393.2020.9255028. Final version is available at 


\title{
Model-based Electronic Expansion Valve Feed-forward Control for Electrified Automotive Vapor Compression Refrigeration System
}

\author{
Jan Glos*, František Šolc ${ }^{\dagger}$, Pavel Václavek ${ }^{\ddagger}$ \\ CEITEC - Central European Institute of Technology \\ Brno University of Technology \\ Brno, Czech Republic \\ * ORCID ID 0000-0001-9636-1529, ${ }^{\dagger}$ Email: frantisek.solc@ @eitec.vutbr.cz, ${ }^{\ddagger}$ ORCID ID 0000-0001-8624-5874
}

\begin{abstract}
This paper presents a model-based method of electronic expansion valve feed-forward control for the automotive vapor compression refrigeration system. The model of the refrigeration system was assembled and the equation for expansion valve effective flow area was then derived. The computation of the expansion valve opening ratio is based on the system model and correction controller. The presented approach of expansion valve control was implemented on a test bench and successfully verified in real operation.

Index Terms-electronic expansion valve, EXV, subcooling control, automotive refrigeration, vapor compression refrigeration system, VCRS, electric vehicle, EV, heating, ventilation, air conditioning, HVAC, R1234yf, feed-forward control, dynamic model
\end{abstract}

\section{INTRODUCTION}

Energy-efficient control of Vapor Compression Refrigeration Systems (VCRS) is getting more and more important with the coming age of Electric Vehicles (EV). In contrast to Internal Combustion Engine (ICE) vehicles, where the VCRS only increases the fuel consumption, for EV the VCRS and especially compressor power consumption can substantially affect the vehicle range, which is already limited.

VCRS systems are used in the automotive industry for a long time, but recently the development was accelerated due to EV advent. The VCRS for ICE vehicles is moreover isolated from other subsystems of the vehicle. On the other hand, for EV the VCRS is usually an integral part of Vehicle Thermal Management System (VTMS), which also addresses Highvoltage Battery conditioning, cabin heating, Electric Drive cooling, and possibly others. A comprehensive overview of different VTMS layouts can be found for example in [1].

Considering only the VCRS system, there are two main configurations possible, a system with a high-pressure receiver complemented by evaporator superheat control, and a system with a low-pressure accumulator with a fixed orifice. In this paper we consider a combination of these types, the target system has a low-pressure accumulator and it is also equipped with Electronic Expansion Valve (EXV) instead of an orifice. This configuration brings new possibilities of efficient control employing the EXV control.
Utilization of EXVs instead of a combination of Shutoff Valve (SOV) with an orifice or Thermostatic Expansion Valve (TXV) has also a significant positive effect on system performance and efficiency [2].

VCRS with a suction accumulator has an additional degree of freedom compared to a system with a liquid line receiver, where the expansion valve (XV) is controlled to ensure the required superheat at the compressor inlet. The accumulator safeguards that no liquid refrigerant will flow into the compressor, thus the EXV can be used for the optimization of VCRS operation.

It was found in [3] that condenser subcooling (SC) has a significant influence on the Coefficient of Performance (COP) and several methods of optimal SC determination were introduced in [4]-[6]. An online method based on Extremum seeking control (ESC) was presented in [7] with a perceptible positive effect on system efficiency.

The particular EXV control for fulfilling the subcooling or superheat reference can be realized by multiple approaches. The state-of-the-art for EXV control is the application of a PI or PID controller for superheat control [8]. The PID control, fuzzy control, and artificial neural network control were implemented for superheat control in [9]. There are also applications of Model Predictive Control (MPC) for VCRS control [10]-[13]. A more exhaustive overview of possible approaches can be found in [14].

It needs to be mentioned that most of the control approaches cited above are suitable for large and/or stationary VCRS applications. Nevertheless, the automotive applications usually require slightly different techniques as the behavior is substantially faster and the operating conditions and user requirements can quickly change.

\section{Motivation \& GOAL}

Compressor speed (and thus cooling/heating power) can be quite easily controlled (e.g. by PI controller, optionally with gain scheduling based on evaporator air mass flow rate and/or chiller coolant mass flow rate) to defined pressure reference (usually the pressure of $3-4$ bar). 


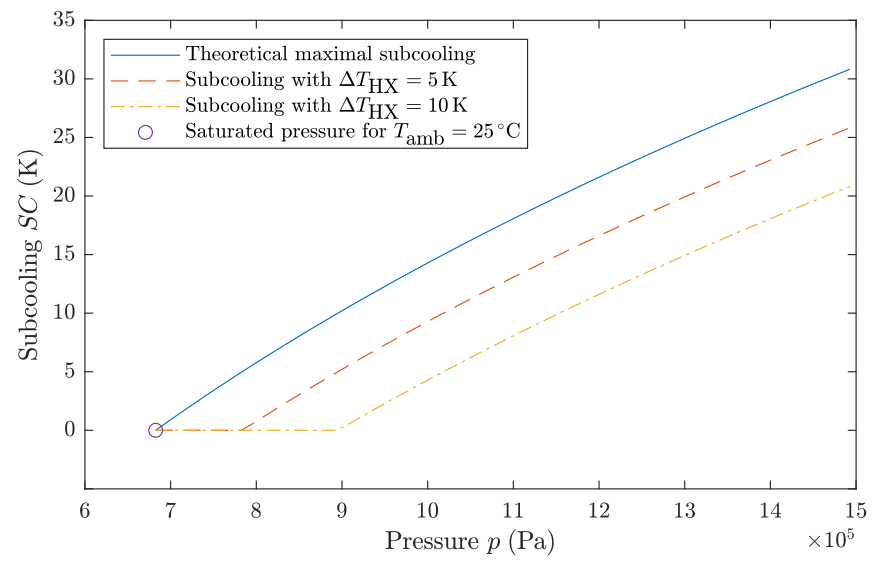

Fig. 1: Dependency of condenser subcooling on refrigerant pressure (R1234yf) for ambient temperature $T_{\mathrm{amb}}=25^{\circ} \mathrm{C}$

EXV control is much more tricky - in VCRS with suction accumulator the EXV should ensure defined condenser subcooling (e.g. $5-10 \mathrm{~K}$; representing optimal COP). Issues of a simple PI controller approach are:

1) Reduced VCRS performance during startup - EXV is almost closed due to low or even none subcooling (will be discussed later), thus the low-side pressure goes below the defined pressure reference and compressor speed is significantly reduced by its speed control.

2) Subcooling (SC) measurement - subcooling is defined and measurable (computable) only for positive values (even if the refrigerant is far in the two-phase region, the subcooling virtual sensor always reports $0 \mathrm{~K}$ ). If $\mathrm{SC}$ setpoint is $5 \mathrm{~K}$ then maximum control error is $+5 \mathrm{~K}$ and for refrigerant of quality $\xi \in(0,1)$ will be always the same. Despite that SC should be positive during the whole operation, the decrease to $0 \mathrm{~K}$ can easily happen during startup or fast condenser air mass flow rate change.

If we consider VCRS startup, we can observe zero or low $\mathrm{SC}$ values during the first tenths seconds of operation. This phenomenon is caused by SC's definition and its properties, especially the dependence on high-side pressure. The blue line in Fig. 1 shows the maximal theoretical value of SC for different pressure values under the assumption that the refrigerant is cooled down exactly to ambient temperature in the condenser. As this assumption usually does not hold for a real condenser, two characteristics were added into Fig. 1. Symbol $\Delta T_{\mathrm{HX}}$ represents the temperature difference between ambient temperature and refrigerant temperature at the condenser outlet. If we consider the worst presented case $\left(\Delta T_{\mathrm{HX}}=10 \mathrm{~K}\right)$, the $\mathrm{SC}$ value is equal to zero for pressure below 9 bar and then it gradually rises. Thus the classical approach with PI controller would restrict the EXV refrigerant mass flow rate (e.g. it will see zero or low SC until reaching 11 bar for SC reference of $7 \mathrm{~K}$ ).

As it was found that the more advanced control approach is desirable, we need to define its goals. First of all, the EXV should be controlled to keep the refrigerant subcooled (to avoid refrigerant flow reduction due to vapor bubbles), then the SC value should track the SC reference and obviously, the whole VCRS should provide desired cooling capacity (even during startup). We identified several possible solutions, which would satisfy some or all of the goals.

1) Compressor startup by ramp - ramp final value needs to be defined, some switching to controller needed, very low suction pressure, still quite low performance (due to low refrigerant mass flow rate in the evaporator).

2) EXV startup value - the value and the validity time needs to be defined, probably dependent on operating conditions and compressor speed.

3) Higher low limit of EXV opening - depends on operating conditions; would need to be adjusted (probably online), could lead to no SC (if more closed EXV required).

4) EXV control based on refrigerant mass flow rate computation - low pressure not dropping so much, performance not reduced, dependent on the accuracy of $\dot{m}$ guess value.

5) EXV control based on the VCRS model - EXV can be controlled to specific enthalpy instead of SC (valid also in two phase-area), more precise $\dot{m}$ computation.

The fourth method was selected as it should fulfill the defined goals and it is quite easily implementable and tunable. The fifth method would also provide the required performance, but the deployment would be much more complicated, so it could be the next step in our research activities.

\section{VCRS MODEL}

The VCRS model was derived and assembled to enable realtime computations of required variables. The model consists of a compressor, an expansion valve and two heat exchangers (evaporator and condenser). The components of the model are briefly described within this section and then interconnected to represent a VCRS circuit model (Fig. 2). Some phenomena (like moisture air etc.) are not described in this paper, as they are modelled using commonly-known equations, and their detailed explanation is not strictly necessary for the control approach understanding.

\section{A. Expansion valve}

We reuse the commonly used expansion valve mass flow rate equation [15]-[20]

$$
\dot{m}_{\mathrm{xv}}=C_{\mathrm{d}} A \sqrt{2 \rho_{\mathrm{xv}, \mathrm{i}}\left(p_{\mathrm{c}}-p_{\mathrm{e}}\right)},
$$

where $\dot{m}_{\mathrm{xv}}$ is the refrigerant mass flow rate, $C_{\mathrm{d}}$ is $\mathrm{EXV}$ discharge coefficient, $A$ stands for effective flow area, $\rho_{\mathrm{xv}, \mathrm{i}}$ is the refrigerant volumetric mass density at EXV inlet and $p_{\mathrm{c}}, p_{\mathrm{e}}$ are inlet and outlet pressures respectively.

We then assume that the expansion process is isenthalpic, i.e.

$$
h_{\mathrm{o}}=h_{\mathrm{i}},
$$

where $h_{\mathrm{i}}$ and $h_{\mathrm{o}}$ are EXV inlet and outlet refrigerant specific enthalpy respectively. 


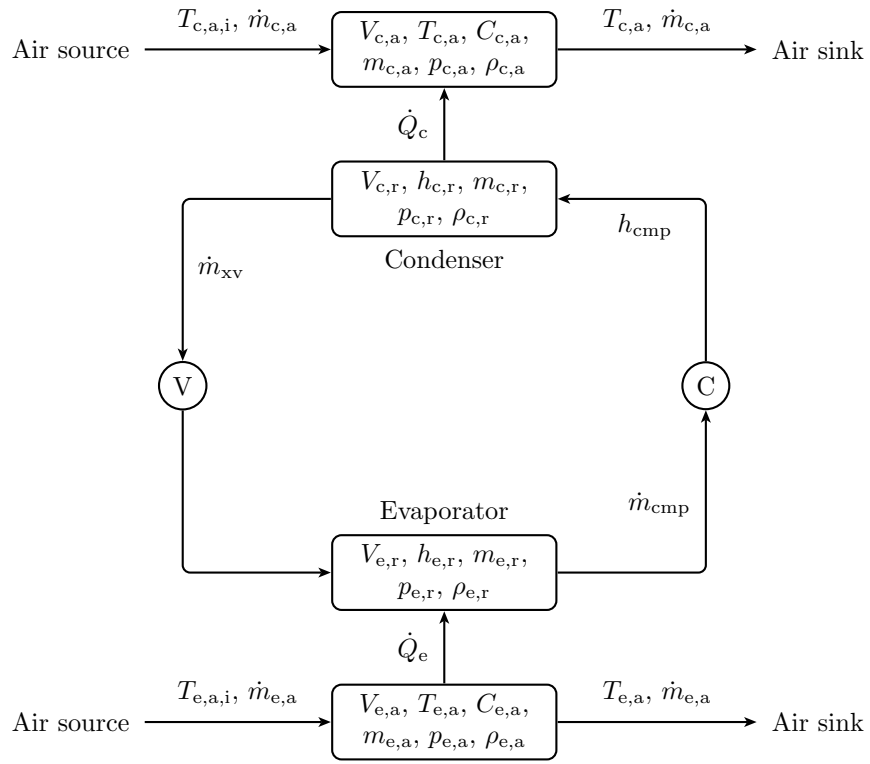

Fig. 2: VCRS model schematics

\section{B. Compressor model}

The compressor refrigerant mass flow rate can be described by

$$
\dot{m}_{\mathrm{cmp}}=\frac{\omega}{2 \pi} \rho_{\mathrm{cmp}, \mathrm{i}} V_{\mathrm{cmp}} \eta_{\mathrm{vol}},
$$

which was adapted from [20] and where $\dot{m}_{\mathrm{cmp}}$ is compressor refrigerant mass flow rate, $\omega$ is compressor shaft angular speed, $\rho_{\text {cmp,i }}$ stands for refrigerant volumetric mass density at the suction side, $V_{\mathrm{cmp}}$ is compressor displacement and $\eta_{\mathrm{vol}}$ is compressor volumetric efficiency.

The compressor outlet refrigerant enthalpy equation can be written as

$$
h_{\mathrm{o}}=h_{\mathrm{i}}+\frac{h_{\mathrm{o}, \mathrm{ie}}-h_{\mathrm{i}}}{\eta_{\mathrm{ie}}},
$$

where $h_{\mathrm{i}}$ and $h_{\mathrm{o}}$ are refrigerant specific enthalpies at the compressor inlet and outlet respectively, $\eta_{\mathrm{ie}}$ is isentropic efficiency and isentropic enthalpy $h_{\mathrm{o} \text {,ie }}$ can be obtained from tables as $h_{\mathrm{o}, \text { ie }}=\mathrm{h}\left(p_{\mathrm{o}}, s\right)$, where $s=\mathrm{s}\left(p_{\mathrm{i}}, h_{\mathrm{i}}\right)$ with $p_{\mathrm{i}}$ and $p_{\mathrm{o}}$ being refrigerant pressure at the compressor inlet and outlet respectively. If the compressor motor and power electronics are cooled by the refrigerant, (4) needs to be modified to

$$
h_{\mathrm{o}}=h_{\mathrm{i}}+\frac{h_{\mathrm{o}, \mathrm{ie}}-h_{\mathrm{i}}}{\eta_{\mathrm{ie}} \eta_{\mathrm{m}} \eta_{\mathrm{mot}}},
$$

where $\eta_{\mathrm{m}}$ and $\eta_{\text {mot }}$ are mechanical and motor efficiencies respectively.

\section{Heat exchanger model}

The heat exchanger model is based on a lumped-parameter approach and it is inspired by [21]. The described model employs only one cell per each exchanger for model simplicity, but it could be easily modified to multiple cells approach.

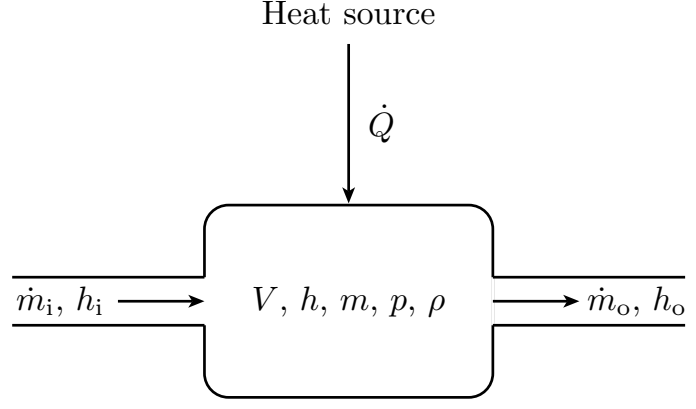

Fig. 3: Heat exchanger refrigerant cell

$$
\begin{aligned}
\frac{\mathrm{d} h}{\mathrm{~d} t} & =\frac{1}{m}\left(\dot{Q}+\dot{m}_{\mathrm{i}}\left(h_{\mathrm{i}}-h_{\mathrm{o}}\right)+V \frac{\mathrm{d} p}{\mathrm{~d} t}\right), \\
\frac{\mathrm{d} p}{\mathrm{~d} t} & =\frac{\frac{\dot{m}_{\mathrm{i}}-\dot{m}_{\mathrm{o}}}{V}-\left(\frac{\partial \rho}{\partial h}\right)_{p} \frac{\mathrm{d} h}{\mathrm{~d} t}}{\left(\frac{\partial \rho}{\partial p}\right)_{h}}, \\
\Delta p & =p_{\mathrm{i}}-p_{\mathrm{o}}, \\
m & =V \bar{\rho}, \\
\bar{\rho} & =\rho(\bar{h}, p) .
\end{aligned}
$$

This set of equations contains an algebraic loop (terms $\frac{\mathrm{d} p}{\mathrm{~d} t}$ and $\frac{\mathrm{d} h}{\mathrm{~d} t}$ in equations right-hand side). We reorder the equations to eliminate the algebraic loop with the following result

$$
\begin{aligned}
& \frac{\mathrm{d} h}{\mathrm{~d} t}=\frac{\left(\frac{\partial \rho}{\partial p}\right)_{h}\left(\dot{Q}+\dot{m}_{\mathrm{i}}\left(h_{\mathrm{i}}-h\right)\right)+\dot{m}_{\mathrm{i}}-\dot{m}_{\mathrm{o}}}{m\left(\frac{\partial \rho}{\partial p}\right)_{h}+V\left(\frac{\partial \rho}{\partial h}\right)_{p}}, \\
& \frac{\mathrm{d} p}{\mathrm{~d} t}=\frac{m\left(\dot{m}_{\mathrm{i}}-\dot{m}_{\mathrm{o}}\right)-V\left(\frac{\partial \rho}{\partial h}\right)_{p}\left(\dot{Q}+\dot{m}_{\mathrm{i}}\left(h_{\mathrm{i}}-h\right)\right)}{V\left(m\left(\frac{\partial \rho}{\partial p}\right)_{h}+V\left(\frac{\partial \rho}{\partial h}\right)_{p}\right)},
\end{aligned}
$$

which is more preferable for computations, but the native physical view of the cell behavior got lost.

\section{Overall VCRS model}

The overall VCRS model was assembled as a combination of separate models described above.

The model state variables are refrigerant pressures $p$, refrigerant specific enthalpies $h$ and outlet air temperatures $T$, all of them for the condenser (with the subscript "c,m") and evaporator (with the subscript "e,m"), where "m" stands for medium (" $r$ " for refrigerant, "a" for the air). Complementary variables include mass $m$, mass flow rate $\dot{m}$, volume $V$, volumetric mass density $\rho$, heat flow rate $\dot{Q}$ and others.

It is not possible to explain all the used symbols due to space limitation, but most of the symbols are self-described by Fig. 2. Similarly, model calibration and validation are not included in this paper. 


$$
\begin{aligned}
& \frac{\mathrm{d} p_{\mathrm{c}, \mathrm{r}}}{\mathrm{d} t}=\frac{m_{\mathrm{c}, \mathrm{r}}\left(\dot{m}_{\mathrm{cmp}}-\dot{m}_{\mathrm{xv}}\right)-V_{\mathrm{c}, \mathrm{r}}\left(\frac{\partial \rho}{\partial h}\right)_{p}\left(-\dot{Q}_{\mathrm{c}}+\dot{m}_{\mathrm{cmp}}\left(h_{\mathrm{cmp}}-h_{\mathrm{c}, \mathrm{r}}\right)\right)}{V_{\mathrm{c}, \mathrm{r}}\left(m_{\mathrm{c}, \mathrm{r}}\left(\frac{\partial \rho}{\partial p}\right)_{h}+V_{\mathrm{c}, \mathrm{r}}\left(\frac{\partial \rho}{\partial h}\right)_{p}\right)}, \\
& \frac{\mathrm{d} p_{\mathrm{e}, \mathrm{r}}}{\mathrm{d} t}=\frac{m_{\mathrm{e}, \mathrm{r}}\left(\dot{m}_{\mathrm{xv}}-\dot{m}_{\mathrm{cmp}}\right)-V_{\mathrm{e}, \mathrm{r}}\left(\frac{\partial \rho}{\partial h}\right)_{p}\left(\dot{Q}_{\mathrm{e}}+\dot{m}_{\mathrm{xv}}\left(h_{\mathrm{c}, \mathrm{r}}-h_{\mathrm{e}, \mathrm{r}}\right)\right)}{V_{\mathrm{e}, \mathrm{r}}\left(m_{\mathrm{e}, \mathrm{r}}\left(\frac{\partial \rho}{\partial p}\right)_{h}+V_{\mathrm{e}, \mathrm{r}}\left(\frac{\partial \rho}{\partial h}\right)_{p}\right)}, \\
& \frac{\mathrm{d} h_{\mathrm{c}, \mathrm{r}}}{\mathrm{d} t}=\frac{\left(\frac{\partial \rho}{\partial p}\right)_{h}\left(-\dot{Q}_{\mathrm{c}}+\dot{m}_{\mathrm{cmp}}\left(h_{\mathrm{cmp}}-h_{\mathrm{c}, \mathrm{r}}\right)\right)+\dot{m}_{\mathrm{cmp}}-\dot{m}_{\mathrm{xv}}}{m_{\mathrm{c}, \mathrm{r}}\left(\frac{\partial \rho}{\partial p}\right)_{h}+V_{\mathrm{c}, \mathrm{r}}\left(\frac{\partial \rho}{\partial h}\right)_{p}}, \\
& \frac{\mathrm{d} h_{\mathrm{e}, \mathrm{r}}}{\mathrm{d} t}=\frac{\left(\frac{\partial \rho}{\partial p}\right)_{h}\left(\dot{Q}_{\mathrm{e}}+\dot{m}_{\mathrm{xv}}\left(h_{\mathrm{c}, \mathrm{r}}-h_{\mathrm{e}, \mathrm{r}}\right)\right)+\dot{m}_{\mathrm{xv}}-\dot{m}_{\mathrm{cmp}}}{m_{\mathrm{e}, \mathrm{r}}\left(\frac{\partial \rho}{\partial p}\right)_{h}+V_{\mathrm{e}, \mathrm{r}}\left(\frac{\partial \rho}{\partial h}\right)_{p}}, \\
& h_{\mathrm{cmp}}=h_{\mathrm{e}, \mathrm{r}}+\frac{h_{\mathrm{cmp}, \mathrm{ie}}-h_{\mathrm{e}, \mathrm{r}}}{\eta_{\mathrm{ie}} \eta_{\mathrm{m}} \eta_{\mathrm{mot}}}, \\
& h_{\mathrm{cmp}, \mathrm{ie}}=\mathrm{h}\left(p_{\mathrm{c}, \mathrm{r}}, s_{\mathrm{e}, \mathrm{r}}\right) \text {, } \\
& \dot{m}_{\mathrm{cmp}}=\frac{\omega}{2 \pi} \rho_{\mathrm{e}, \mathrm{r}} V_{\mathrm{cmp}} \eta_{\mathrm{vol}} \text {, } \\
& \dot{m}_{\mathrm{xv}}=C_{\mathrm{d}} A \sqrt{2 \rho_{\mathrm{c}, \mathrm{r}}\left(p_{\mathrm{c}, \mathrm{r}}-p_{\mathrm{e}, \mathrm{r}}\right)}, \\
& \frac{\mathrm{d} T_{\mathrm{c}, \mathrm{a}}}{\mathrm{d} t}=\frac{1}{C_{\mathrm{c}, \mathrm{a}}}\left[\dot{m}_{\mathrm{c}, \mathrm{a}} \mathrm{c}_{\mathrm{p}, \mathrm{a}}\left(T_{\mathrm{c}, \mathrm{a}, \mathrm{i}}-T_{\mathrm{c}, \mathrm{a}}\right)+\dot{Q}_{\mathrm{c}}\right], \\
& \frac{\mathrm{d} T_{\mathrm{e}, \mathrm{a}}}{\mathrm{d} t}=\frac{1}{C_{\mathrm{e}, \mathrm{a}}}\left[\dot{m}_{\mathrm{e}, \mathrm{a}} \mathrm{c}_{\mathrm{p}, \mathrm{a}}\left(T_{\mathrm{e}, \mathrm{a}, \mathrm{i}}-T_{\mathrm{e}, \mathrm{a}}\right)-\dot{Q}_{\mathrm{e}, \mathrm{a}}\right], \\
& \dot{Q}_{\mathrm{c}}=U_{\mathrm{c}} A_{\mathrm{c}} \Delta T_{\mathrm{c}} \\
& \dot{Q}_{\mathrm{e}}=\dot{Q}_{\mathrm{e}, \mathrm{a}}+\dot{Q}_{\mathrm{e}, \mathrm{v}}, \\
& \dot{Q}_{\mathrm{e}, \mathrm{a}}=U_{\mathrm{e}} A_{\mathrm{e}} \Delta T_{\mathrm{e}}, \\
& \dot{Q}_{\mathrm{e}, \mathrm{v}}=0.622 \dot{m}_{\mathrm{e}, \mathrm{a}, \mathrm{i}} L\left[\frac{\phi_{\mathrm{e}, \mathrm{i}} p_{\mathrm{V}}^{*}\left(T_{\mathrm{e}, \mathrm{a}, \mathrm{i}}\right)}{p-\phi_{\mathrm{e}, \mathrm{i}} p_{\mathrm{V}}^{*}\left(T_{\mathrm{e}, \mathrm{a}, \mathrm{i}}\right)}-\frac{p_{\mathrm{V}}^{*}\left(T_{\mathrm{e}, \mathrm{r}}\right)}{p-p_{\mathrm{V}}^{*}\left(T_{\mathrm{e}, \mathrm{r}}\right)}\right], \\
& p_{\mathrm{V}}^{*}\left(T_{\mathrm{e}, \mathrm{a}, \mathrm{i}}\right)=p_{0} \exp \left\{\left[\frac{h_{\mathrm{fg}}}{R}\left(\frac{1}{T_{0}}-\frac{1}{T_{\mathrm{e}, \mathrm{a}, \mathrm{i}}}\right)\right]\right\}, \\
& p_{\mathrm{V}}^{*}\left(T_{\mathrm{e}, \mathrm{r}}\right)=p_{0} \exp \left\{\left[\frac{h_{\mathrm{fg}}}{R}\left(\frac{1}{T_{0}}-\frac{1}{T_{\mathrm{e}, \mathrm{r}}}\right)\right]\right\}, \\
& \Delta T_{\mathrm{e}}=\frac{\Delta T_{1}-\Delta T_{2}}{\ln \frac{\Delta T_{1}}{\Delta T_{2}}}=\frac{\left(T_{\mathrm{e}, \mathrm{a}, \mathrm{i}}-T_{\mathrm{e}, \mathrm{r}}\right)-\left(T_{\mathrm{e}, \mathrm{a}}-T_{\mathrm{e}, \mathrm{r}}\right)}{\ln \frac{\left(T_{\mathrm{e}, \mathrm{a}, \mathrm{i}}-T_{\mathrm{e}, \mathrm{r}}\right)}{\left(T_{\mathrm{e}, \mathrm{a}}-T_{\mathrm{e}, \mathrm{r}}\right)}}, \\
& \Delta T_{\mathrm{c}}=\frac{\Delta T_{1}-\Delta T_{2}}{\ln \frac{\Delta T_{1}}{\Delta T_{2}}}=\frac{\left(T_{\mathrm{c}, \mathrm{r}}-T_{\mathrm{c}, \mathrm{a}, \mathrm{i}}\right)-\left(T_{\mathrm{c}, \mathrm{r}}-T_{\mathrm{c}, \mathrm{a}}\right)}{\ln \frac{\left(T_{\mathrm{c}, \mathrm{r}}-T_{\mathrm{c}, \mathrm{a}, \mathrm{i}}\right)}{\left(T_{\mathrm{c}, \mathrm{r}}-T_{\mathrm{c}, \mathrm{a}}\right)}}, \\
& T_{\mathrm{c}, \mathrm{r}}=\mathrm{T}_{\mathrm{sat}}\left(p_{\mathrm{c}, \mathrm{r}}\right) \text {, } \\
& T_{\mathrm{e}, \mathrm{r}}=\mathrm{T}_{\mathrm{sat}}\left(p_{\mathrm{e}, \mathrm{r}}\right) \text {, } \\
& m_{\mathrm{c}, \mathrm{r}}=V_{\mathrm{c}, \mathrm{r}} \rho\left(\bar{h}_{\mathrm{c}, \mathrm{r}}, p_{\mathrm{c}, \mathrm{r}}\right) \text {, } \\
& m_{\mathrm{e}, \mathrm{r}}=V_{\mathrm{e}, \mathrm{r}} \rho\left(\bar{h}_{\mathrm{e}, \mathrm{r}}, p_{\mathrm{e}, \mathrm{r}}\right) \text {. }
\end{aligned}
$$

\section{VCRS CONTROL}

Using (3) we can compute the expected refrigerant mass flow rate of the compressor and by employing (1) we can get the mass flow rate through the EXV.

In steady-state we suppose that these refrigerant mass flow rates are equal

$$
\dot{m}_{\mathrm{xv}}=\dot{m}_{\mathrm{cmp}} .
$$

By combining (1) and (3) and by some reordering we can get an equation for estimated EXV effective area needed for steady-state VCRS operation

$$
A=\frac{\frac{\omega}{2 \pi} \rho_{\mathrm{cmp}, \mathrm{i}} V_{\mathrm{cmp}} \eta_{\mathrm{vol}}}{C_{\mathrm{d}} \sqrt{2 \rho_{\mathrm{xv}, \mathrm{i}}\left(p_{\mathrm{c}}-p_{\mathrm{e}}\right)}} .
$$

We know almost all of the variables used, but particularly refrigerant volumetric mass densities at the compressor and EXV inlet are not precisely known.

Regarding the compressor inlet refrigerant density, the situation is quite clear. If we measure the evaporator pressure

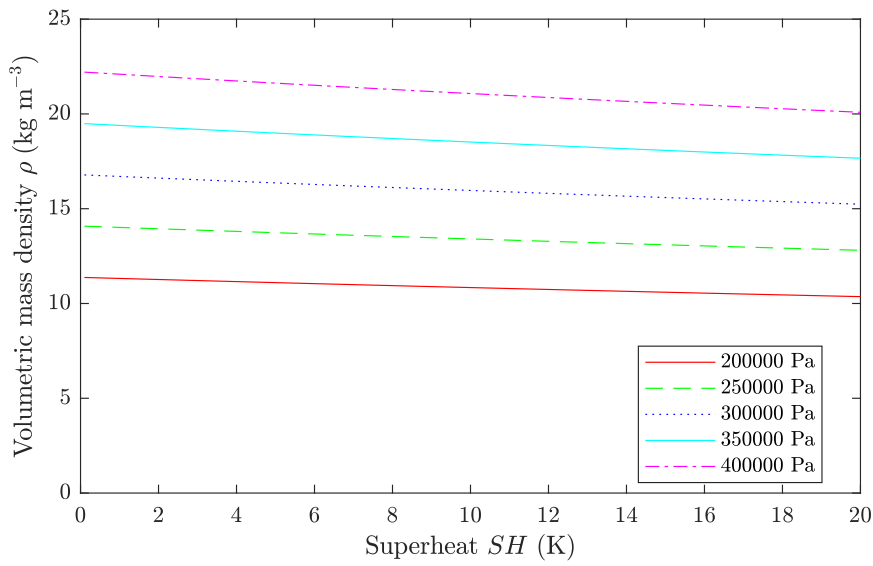

Fig. 4: R1234yf volumetric mass density dependency on superheat for different evaporator pressure levels

(suction pressure), we can then get the refrigerant mass density from refrigerant tables as a function

$$
\rho_{\mathrm{cmp}, \mathrm{i}}=\rho\left(p_{\mathrm{e}}, h_{\mathrm{e}}\right) .
$$

The VCRS circuit is equipped with a suction line accumulator, which ensures no liquid refrigerant in compressor suction (i.e. the quality of refrigerant is always equal 1 or even superheated). Then we can simplify (37) as a function of a single variable

$$
\rho_{\mathrm{cmp}, \mathrm{i}}=\rho_{\mathrm{sv}}\left(p_{\mathrm{e}}\right),
$$

where $\rho_{\mathrm{sv}}\left(p_{\mathrm{e}}\right)$ is a function returning refrigerant mass density based on refrigerant pressure $p$ at saturated vapor line. We neglect the changes of refrigerant mass density caused by possible refrigerant superheating in the evaporator or pipe between the accumulator and compressor, but it is evident from Fig. 4 that it has a negligible impact on refrigerant mass density (under usual operating conditions).

The second unknown variable is the refrigerant mass density at EXV inlet. In this case, we need to investigate the possibilities in more detail. Under fixed pressure (we can measure) we can get dependency of refrigerant density on specific enthalpy (Fig. 5) and this would give us the best possible results

$$
\rho_{\mathrm{xv}, \mathrm{i}}=\rho\left(p_{\mathrm{c}}, h_{\mathrm{c}}\right),
$$

but the specific enthalpy can not be directly measured or simply computed. In mentioned Fig. 5 the refrigerant mass density for saturated liquid is highlighted by a small circle. The only measurable variable - subcooling - can be computed using

$$
S C=\mathrm{T}_{\mathrm{sl}}\left(p_{\mathrm{c}}\right)-T_{\mathrm{ref}},
$$

where $\mathrm{T}_{\mathrm{sl}}(p)$ is a function returning refrigerant temperature based on its pressure on the saturated liquid line and $T_{\text {ref }}$ is measured refrigerant temperature at condenser outlet.

If we investigate the volumetric mass density dependency on subcooling in Fig. 6, we can simplify the (39) to the function 


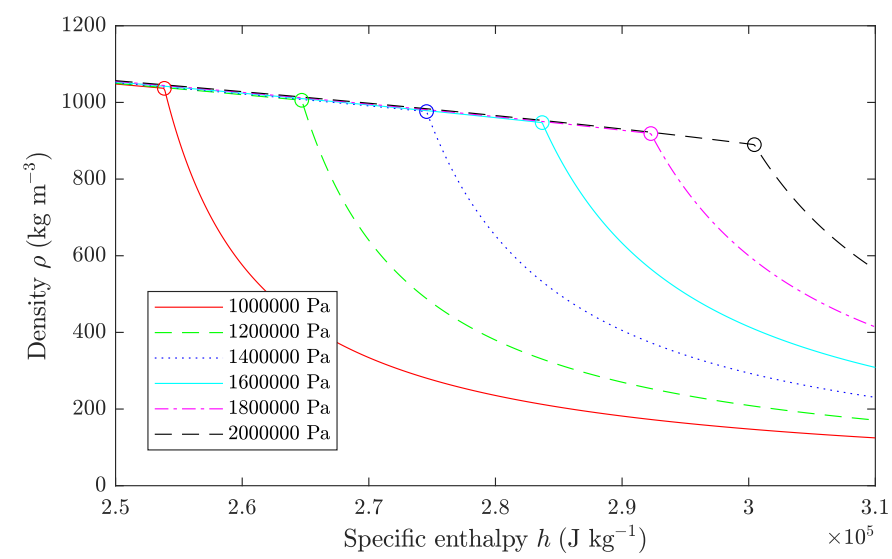

Fig. 5: R1234yf volumetric mass density dependency on specific enthalpy for different condenser pressure levels

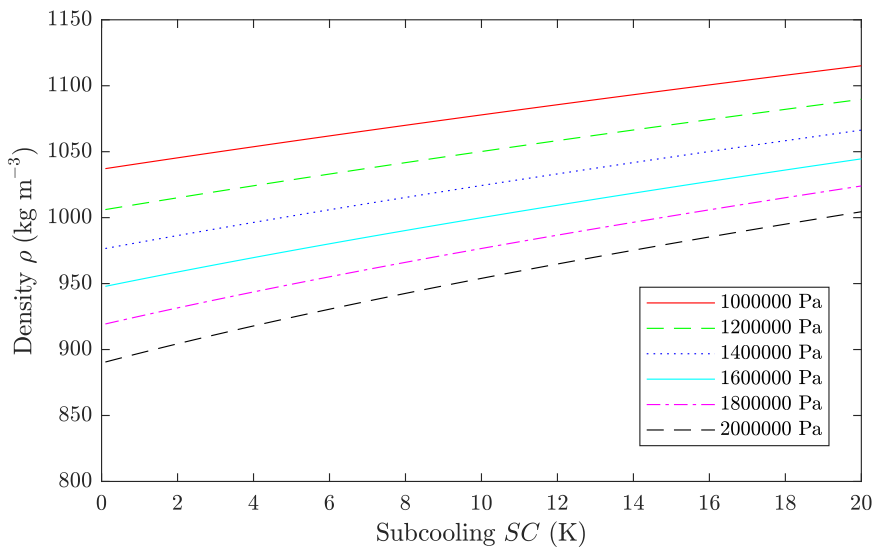

Fig. 6: R1234yf mass density dependency on refrigerant subcooling for different condenser pressure levels

of a single variable, as the density variation due to subcooling can be neglected for reasonable values of subcooling

$$
\rho_{\mathrm{xv}, \mathrm{i}}=\rho_{\mathrm{sl}}\left(p_{\mathrm{c}}\right)
$$

where $\rho_{\mathrm{sl}}(p)$ is a function returning the refrigerant quality based on its pressure at the saturated liquid line. We could also omit this neglection and compute the mass density as

$$
\rho_{\mathrm{xv}, \mathrm{i}}=\rho\left(p_{\mathrm{c}}, S C\right),
$$

but the accuracy improvement would not be significant.

On the other hand, we can not extend the simplification in (41) to the two-phase region, as the refrigerant mass density is strongly dependent on refrigerant quality. This dependency is illustrated in Fig. 7.

Then we have two possibilities of EXV mass density computation. The first one presumes subcooled refrigerant throughout whole the operation and this approach was used within this work. The second one requires the value of specific enthalpy, which can be obtained by executing the VCRS model during its operation. This approach can be the direction of future research and developments.

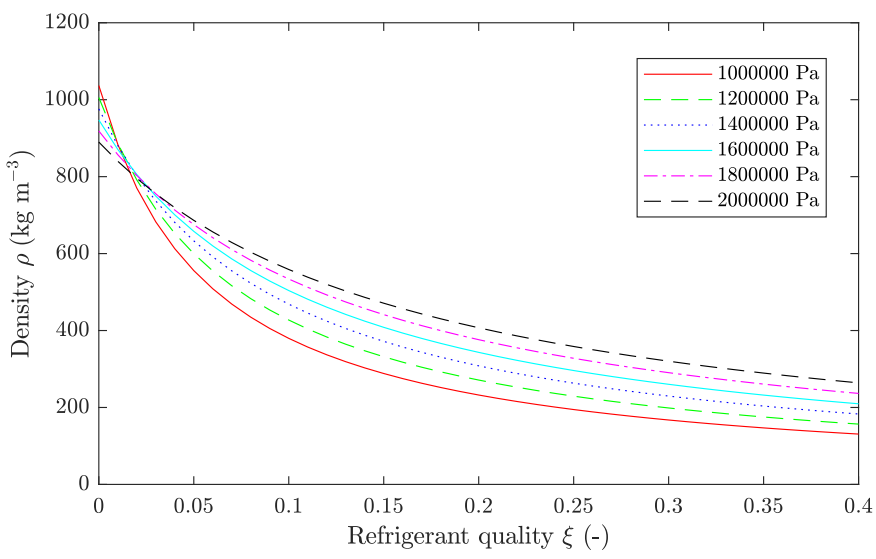

Fig. 7: R1234yf mass density dependency on refrigerant quality for different condenser pressure levels

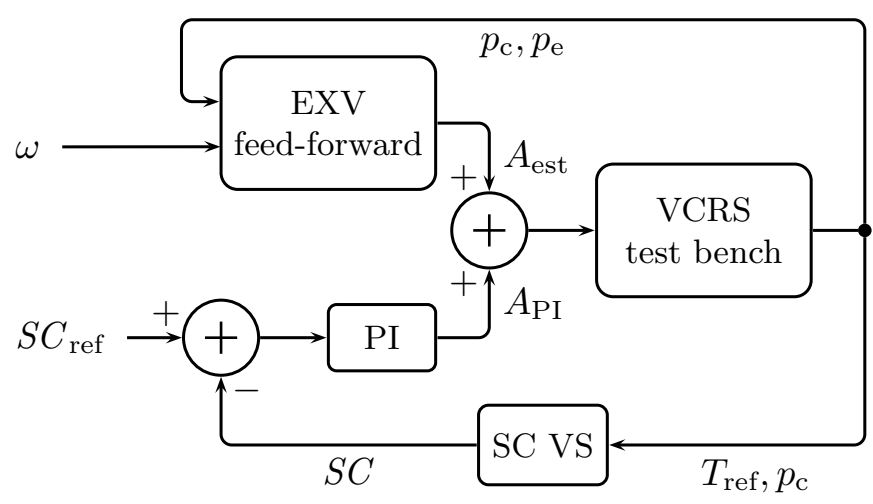

Fig. 8: Model-based VCRS EXV control loops.

We recall (36) and substitute functions for refrigerant mass density

$$
A=\frac{\frac{\omega}{2 \pi} \rho_{\mathrm{sv}}\left(p_{\mathrm{e}}\right) V_{\mathrm{cmp}} \eta_{\mathrm{vol}}}{C_{\mathrm{d}} \sqrt{2 \rho_{\mathrm{sl}}\left(p_{\mathrm{c}}\right)\left(p_{\mathrm{c}}-p_{\mathrm{e}}\right)}}
$$

and using this equation we can compute the estimated effective flow area of EXV. As we made some simplifications (neglecting the influence of superheat and subcooling on refrigerant mass density), there will be some error. It might be also caused by inaccurate EXV model, disturbances and other influences.

We propose adding a PI controller to ensure disturbance rejection and to control the subcooling to optimal reference value with no steady-state error as shown in Fig. 8. This method does not require any additional sensors compared to the baseline (two pressures and refrigerant temperature at the condenser outlet).

\section{EXPERIMENTAL VERIFICATION}

This approach of EXV control was implemented into the control unit based on AURIX Tricore and evaluated on the test bench (Fig. 9) with the results presented in Fig. 10. It is evident that this control approach gives great results in terms of subcooling reference tracking and substantially improves the VCRS system startup. The first plot shows the 


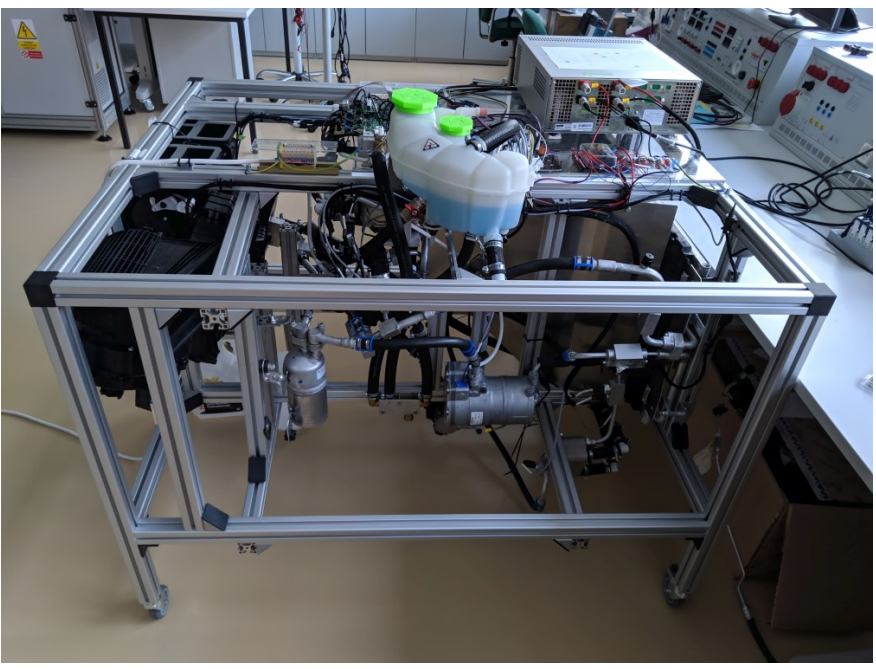

Fig. 9: VCRS test bench

refrigerant pressures including a low-pressure setpoint. It was reached after approx. $150 \mathrm{~s}$ from the compressor start and this time is caused by the conservative setting of the compressor controller (to prevent any oscillations) and by different time constants (caused by e.g. evaporator heat capacity). From the second plot, we can see that VCRS is capable to cool the air and the performance is not limited (even at startup). The evaporator superheat and condenser subcooling are presented in the next plot. The subcooling reference is reached approx. $30 \mathrm{~s}$ after compressor startup and it needs some additional time for settling, but then the reference is tracked without any substantial deviation. The last two plots show the manipulated inputs, the compressor speed, and the EXV opening ratio.

The CoolProp library [22] was used in this paper to obtain refrigerant state variables and other properties.

\section{CONCLUSIONS}

Within this paper, we presented a novel approach to electronic expansion valve control. This approach was successfully implemented and verified for condenser subcooling control, which can contribute to the energy-efficient operation of the vapor compression refrigeration system.

The presented method of EXV SC control could be (with minor changes) also applied to VCRS EXV superheat control.

Future research and development will focus on the improvement of control reliability (control reference will be specific enthalpy value instead of subcooling value) and multievaporator control, which is a quite challenging task for systems with suction line accumulator.

\section{ACKNOWLEDGMENT}

This research was carried out under the project $\mathrm{H} 2020$ 653514 OSEM-EV - Optimised and Systematic Energy Management in Electric Vehicles.

This research has been financially supported by the Ministry of Education, Youth and Sports of the Czech Republic under the project CEITEC 2020 (LQ1601).
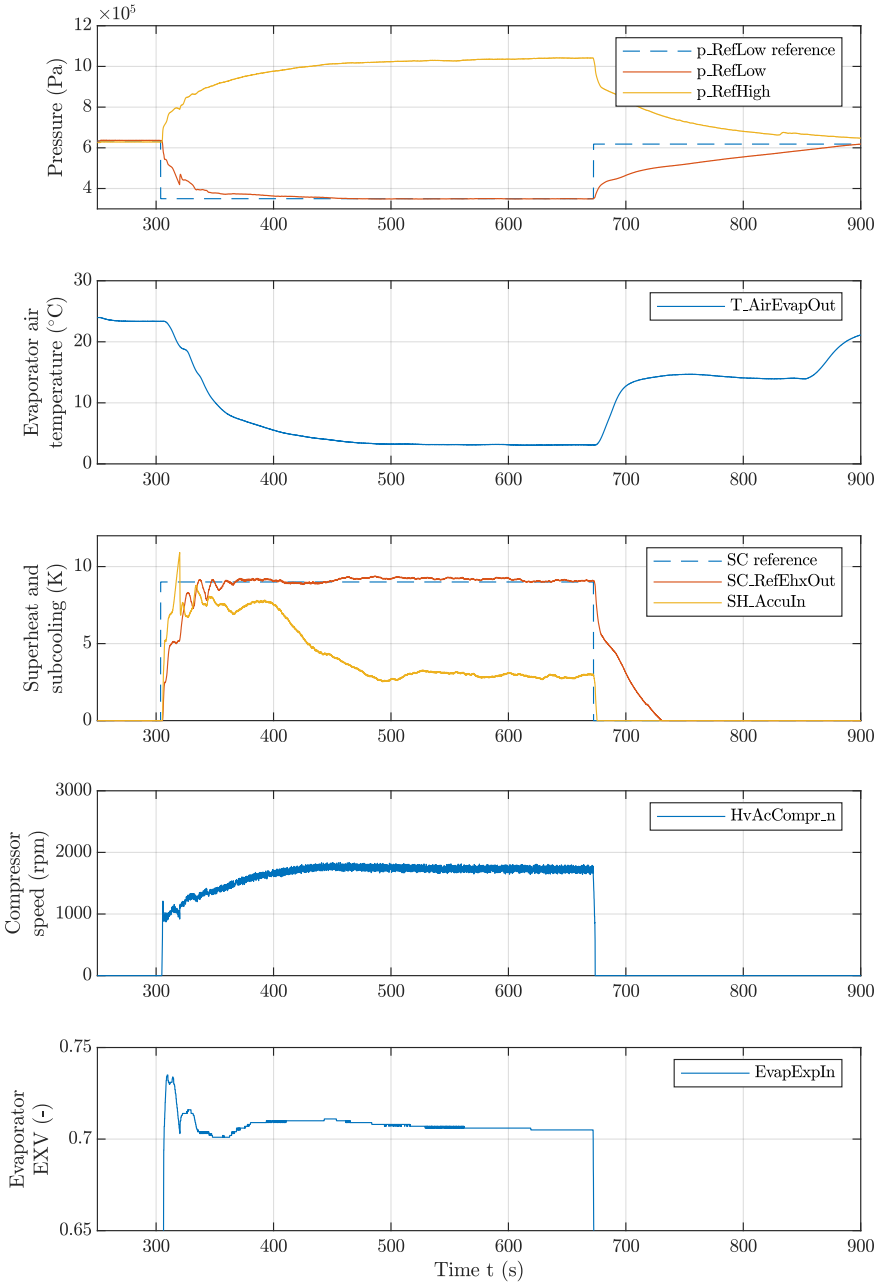

Fig. 10: Test bench measurements of model-based EXV control

\section{REFERENCES}

[1] Z. Zhang, J. Wang, X. Feng, L. Chang, Y. Chen, and X. Wang, "The solutions to electric vehicle air conditioning systems: A review," Renewable and Sustainable Energy Reviews, vol. 91, pp. 443-463, Aug. 2018.

[2] R. Zhang, E. J. Stanke, G. Zhang, Y. Lu, X. Sun, and X. Li, "Benefits investigation of electronic expansion valve in electric vehicle thermal system as compared to thermal expansion valve with shut-off valve," International Journal of Refrigeration, vol. 100, pp. 404-413, Apr. 2019.

[3] G. Pottker, P. Hrnjak, and P. H. Pottker Gustavo, "Effect of Condenser Subcooling of the Performance of Vapor Compression Systems: Experimental and Numerical Investigation," in International Refrigeration and Air Conditioning Conference, vol. 50, pp. 1-10, 2012.

[4] L. Xu and P. Hrnjak, "Potential for Improving Efficiency by Controlling Subcooling in Residential A / C System," International Refrigeration and Air Conditioning Conference, pp. 1-10, 2014.

[5] M. Pitarch, E. Hervas-Blasco, E. Navarro-Peris, J. Gonzálvez-Maciá, and J. M. Corberán, "Evaluation of optimal subcooling in subcritical heat pump systems," International Journal of Refrigeration, vol. 78, pp. 1831, June 2017.

[6] E. Hervas-Blasco, M. Pitarch, E. Navarro-Peris, and J. M. Corberán, "Study of different subcooling control strategies in order to enhance the performance of a heat pump," International Journal of Refrigeration, vol. 88, pp. 324-336, Apr. 2018. 
[7] J. P. Koeln and A. G. Alleyne, "Optimal subcooling in vapor compression systems via extremum seeking control: Theory and experiments," International Journal of Refrigeration, vol. 43, pp. 14-25, 2014.

[8] Z. Zhao and N. Yu, "The application of advanced control technologies in air conditioning system-a review," Advances in Building Energy Research, vol. 11, no. 1, pp. 52-66, 2017.

[9] O. Ekren, S. Sahin, and Y. Isler, "Comparison of different controllers for variable speed compressor and electronic expansion valve," International Journal of Refrigeration, vol. 33, pp. 1161-1168, Sept. 2010.

[10] X. Yin and S. Li, "Energy efficient predictive control for vapor compression refrigeration cycle systems," IEEE/CAA Journal of Automatica Sinica, vol. 5, pp. 953-960, Sept. 2018.

[11] M. Wallace, P. Mhaskar, J. House, and T. Salsbury, "Offset-free model predictive controller of a heat pump," in 2014 American Control Conference, pp. 2247-2252, IEEE, June 2014.

[12] M. Gräber, C. Kirches, J. P. Schlöder, and W. Tegethoff, "Nonlinear Model Predictive Control of a Vapor Compression Cycle based on First Principle Models," IFAC Proceedings Volumes, vol. 45, no. 2, pp. 258$263,2012$.

[13] X. H. Yin and S. Y. Li, "Model Predictive Control for Vapor Compression Cycle of Refrigeration Process," International Journal of Automation and Computing, vol. 15, pp. 707-715, Dec. 2018.

[14] A. Goyal, M. A. Staedter, and S. Garimella, "A review of control methodologies for vapor compression and absorption heat pumps," International Journal of Refrigeration, vol. 97, pp. 1-20, Jan. 2019.

[15] Q. Zhang and M. Canova, "Modeling and output feedback control of automotive air conditioning system," International Journal of Refrigeration, vol. 58, pp. 207-218, Oct. 2015.
[16] Q. Zhang, S. E. Li, and K. Deng, Automotive air conditioning: Optimization, control and diagnosis. Springer International Publishing, Jan. 2016.

[17] P. Deutsch and A. Harris, "Thermodynamic model of electric vehicle A/C system with single evaporator," in Institution of Mechanical Engineers - VTMS 2011, Vehicle Thermal Management Systems Conference Proceedings, pp. 241-249, Woodhead Publishing Limited, 2013.

[18] N. Park, J. Shin, and B. Chung, "A new dynamic heat pump simulation model with variable speed compressors under frosting conditions," in Institution of Mechanical Engineers - 8th International Conference on Compressors and Their Systems, pp. 681-696, Woodhead Publishing Limited, 2013.

[19] I. W. Eames, A. Milazzo, and G. G. Maidment, "Modelling thermostatic expansion valves," International Journal of Refrigeration, vol. 38, pp. 189-197, Feb. 2014.

[20] Y. Shang, A. Wu, X. Fang, and Y. You, "Dynamic simulation of electronic expansion valve controlled refrigeration system under different heat transfer conditions," International Journal of Refrigeration, vol. 72, pp. 41-52, Dec. 2016.

[21] Q. Zhang, S. Stockar, and M. Canova, "Energy-Optimal Control of an Automotive Air Conditioning System for Ancillary Load Reduction,' IEEE Transactions on Control Systems Technology, vol. 24, no. 1, pp. 67-80, 2016.

[22] I. H. Bell, J. Wronski, S. Quoilin, and V. Lemort, "Pure and Pseudopure Fluid Thermophysical Property Evaluation and the Open-Source Thermophysical Property Library CoolProp," Industrial \& Engineering Chemistry Research, vol. 53, no. 6, pp. 2498-2508, 2014. 